\title{
DETECTAR ERROS E FRAUDES NA AUDITORIA CONTÁBIL: UMA ANÁLISE À LUZ DA TEORIA DOS ESCANDÂLOS CORPORATIVOS
}

\author{
Richarde Dezen Junior ${ }^{1}$ \\ Daniela Beduschi ${ }^{2}$ \\ Edileusa Cristina Borçato ${ }^{3}$
}

DEZEN JUNIOR, R.; BEDUSCHI, D.; BORÇATO, E. C. Detectar erros e fraudes na auditoria contábil: uma análise à luz da teoria dos escandâlos corporativos. Rev. Ciênc. Empres. UNIPAR, Umuarama, v. 19, n. 2, p. 291-301, jul./dez. 2018.

RESUMO: O objetivo geral desse estudo foi identificar se a detecção de erros e fraudes é um dos objetivos da contratação da auditoria contábil pelos governantes sob a ótica da teoria dos escândalos corporativos. O mesmo é de natureza qualitativa, quanto aos objetivos é classificado como descritivo, em relação aos procedimentos de pesquisa, é um estudo de caso. A coleta de dados foi realizada por um levantamento através de questionário estruturado com a utilização do software Survio ${ }^{\circledR}$ encaminhado ao auditor interno e gestor, que se delimita à empresa sediada na cidade de Douradina, Estado do Paraná. Os resultados demonstraram que a detecção de erros e fraudes não corresponde ao principal objetivo para contratação da auditoria contábil. Constatou-se que tanto o gestor quanto o auditor entendem que a agregação de valores, redução de custos e melhoria dos processos são os objetivos principais da contratação da auditoria.

PALAVRAS-CHAVE: Auditoria; Erros; Fraudes.

\section{DETECTING ERRORS AND FRAUDS IN ACCOUNTING AUDITS: AN ANALYSIS IN THE LIGHT OF THE CORPORATE SCANDALS THEORY}

\begin{abstract}
The main purpose of this study was to identify if the detection of errors and frauds is one of the objectives when hiring an accounting audit by the managers from the perspective of the theory of corporate scandals. This is a qualitative study, with objectives are classified as descriptive. It can also be

DOI: $10.25110 /$ receu.v19i2.6724

${ }^{1}$ Graduando em Ciências Contábeis pela Universidade Paranaense - UNIPAR, Unidade universitária de Umuarama. juniordezen@hotmail.com

${ }^{2}$ Graduanda em Ciências Contábeis pela Universidade Paranaense - UNIPAR, Unidade universitária de Umuarama. beduschidaniela@hotmail.com

${ }^{3}$ Mestra em Contabilidade, docente na Universidade Paranaense - UNIPAR, Unidade universitária de Umuarama. prof.edileusaborcato@gmail.com
\end{abstract}


defined as a case study due to the research procedures, whose data was collected using a structured questionnaire designed by the software Survio ${ }^{\circledR}$, forwarded to the internal auditor and manager in charge of a company based in the city of Douradina, in the state of Paraná. The results showed that the detection of errors and frauds does not correspond to the main objective for hiring the accounting audit. It was found that both the manager and the auditor consider the aggregation of values, cost reduction and process improvement as the main objectives of an audit.

KEY WORDS: Audit; Errors; Frauds.

\section{DETECTAR ERRORES Y FRAUDES EN LA AUDITORÍA CONTABLE: UN ANÁLISIS A LA LUZ DE LA TEORÍA DE LOS ESCANDALES CORPORATIVOS}

RESUMEN: El objetivo general de este estudio fue identificar si la detección de errores y fraudes es uno de los objetivos de la contratación de la auditoría contable por los gobernantes bajo la óptica de la teoría de los escándalos corporativos. El mismo es de naturaleza cualitativa, en cuanto a los objetivos es clasificado como descriptivo, en relación a los procedimientos de investigación, es un estudio de caso. La recolección de datos fue realizada por un relevamiento a través de un cuestionario estructurado con la utilización del software Survio ${ }^{\circledR}$ encaminado al auditor interno y gestor, que se delimita a la empresa con sede en la ciudad de Douradina, Estado de Paraná. Los resultados demostraron que la detección de errores y fraudes no corresponde al principal objetivo para la contratación de la auditoría contable. Se constató que tanto el gestor como el auditor entienden que la agregación de valores, reducción de costos y mejora de los procesos son los objetivos principales de la contratación de la auditoría.

PALABRAS CLAVE: Auditoría; Errores; Fraude.

\section{INTRODUÇÃO}

Em 1934 nos Estados Unidos, foi criado a Securities Exchange Commission - SEC cujo objetivo era regular o mercado de ações, atuando de forma preventiva nos casos de abusos das corporações, abusos estes que poderiam estar associados à questão da oferta e venda de títulos e de relatórios corporativos. A profissão de auditor se tornou imprescindível, pois para que as empresas possam ingressar na Bolsa de Valores, é necessário que suas demonstrações financeiras sejam auditadas, podendo dessa forma aumentar a credibilidade das informações que são objeto de avaliação pelos investidores. O mesmo aconteceu no Brasil em 1976, com a criação da Comissão de Valores Mobiliários por meio da Lei ${ }^{\circ}$ 


\subsection{5/76 (ATTIE, 1998).}

Etimologicamente a palavra "auditoria" tem a sua origem no verbo latino audire, que significa "ouvir", e que conduziu à criação da palavra "auditor" (do latim auditore) como sendo aquele que ouve. Isto pelo fato de nos primórdios da auditoria os auditores tirarem suas conclusões fundamentadamente com base nas informações verbais que lhes eram transmitidas (RODRIGUES, 2012).

Entende-se assim que a auditoria interna foi criada com o objetivo de fomentar a integridade e a eficiência dos controles internos, podendo dar suporte à equipe administrativa e colaborar com o gerenciamento das empresas, para que dessa forma, possam atingir com sucesso os objetivos almejados. Ou seja, esta atividade busca eliminar sinistros decorrentes de má gestão empresarial (CREPALDI, 2013).

Silva e Inácio (2013) evidenciam que os serviços de auditoria podem ser classificados como internos ou externos, com distintos campos de atuação. De acordo com o grau de confiabilidade existente entre o auditor externo com relação à auditoria interna, pode-se ter a perspectiva do aproveitamento do trabalho realizado pelo auditor interno.

As atribuições do auditor são amplas e podem contribuir para reduzir os principais problemas dessa natureza, pois em média $6 \%$ do faturamento das corporações são perdas por fraudes cometidas por funcionários, como distorções das demonstrações contábeis, incluindo os pedidos falsos e superfaturados e os desvios de dinheiro; sendo essas as práticas mais comuns (CREPALDI, 2013).

Logo, apresenta-se como questão de pesquisa: A constatação de erro ou fraude é um dos principais objetivos da contratação da auditoria contábil? Para responder esta questão têm-se como objetivo geral identificar se a detecção de erros e fraudes é um dos objetivos da contratação da auditoria interna contábil pelo gestor da organização sob a ótica da teoria dos escândalos corporativos.

Como objetivos específicos propõe-se: (a) mapear o perfil do gestor; (b) reconhecer os objetivos da contratação da auditoria interna e independente na visão do gestor; (c) mapear o perfil do auditor.

Os estudos teóricos limitaram-se às obras científicas disponíveis na biblioteca física da Universidade Paranaense - UNIPAR, campus de Umuarama, em bases de dados de revistas científicas eletrônicas das ciências administrativas e contábil. O estudo de caso delimita-se a uma empresa de diversos ramos de atuação instalada na cidade de Douradina - Estado do Paraná.

\section{FUNDAMENTAÇÃO TEÓRICA}

Esta seção apresenta os fundamentos teóricos da auditoria interna, auditoria independente e da teoria dos escândalos corporativos. 


\subsection{Auditoria Interna}

A auditoria interna tem como objetivo agregar valor à entidade, demonstrando subsídios para a gestão, em especial, a melhoria aos controles internos e melhoramento dos processos, por meio da recomendação de soluções para as não conformidades (CFC, 2003).

O trabalho desenvolvido na auditoria interna serve como ferramenta gerencial, possibilita a eficiência dos demais controles da instituição. Nesse ponto fica evidente sua importância ao fomentar administradores em assistência e aconselhamentos. Com este fator chave, o núcleo gerencial tem mais clareza em quais passos dar para alavancar a instituição ou até mesmo onde retroceder, sem que prejudique delegações fiscais.

Logo, entende-se a importância da auditoria interna, que tem a proposta de poder oferecer segurança aos administradores durante as tomadas de decisões e na continuidade das atividades da empresa, assegurando o cumprimento das legislações dos órgãos reguladores e das normas da própria organização (ATTIE, 2011).

$\mathrm{Na}$ atuação em auditoria interna, o funcionário tem vínculo empregatício com a instituição, no entanto possui autonomia para informar os gestores em tempo hábil quando identificar possíveis vestígios de fraude ou erro. Do cotidiano do auditor interno fazem parte as atividades de fornecer análise, recomendações e comentários que auxiliem a trajetória do administrador (CREPALDI, 2013).

Os procedimentos da auditoria interna envolvem exames e testes de observância e testes substantivos que permitem ao ente responsável, indagar informações para auferir conclusões com base nas evidências consideradas provas cabíveis e subsídio para formular conclusões e recomendações da auditoria.

Sua proximidade com o corpo constitucional físico da organização permite ao auditor a possibilidade de averiguar com mais confiabilidade os indícios de possíveis desconformidades operacionais e legais. Para que a haja confiabilidade nos dados e informações fornecidos pelo sistema da organização, aplicam-se os testes substantivos, que permitem a validação dos controles internos.

O conhecimento abrangente do auditor lhe permitirá elaborar o relatório da auditoria interna que compreende objetividade e imparcialidade, expressando de forma clara suas sugestões. Além de abordar objetivos e extensão do trabalho, principais procedimentos, metodologia, limitações, evidências, risos e recomendações referentes à auditoria (CFC, 2003).

A auditoria da área contábil examina todo e qualquer documento que esteja relacionado ao controle do patrimônio da entidade, podendo verificar se estão de acordo com a realidade da empresa e confirmando sua autenticidade nas demonstrações financeiras da empresa. 
Lucas et al. (2014,) citam de forma sucinta o papel e algumas características da auditoria interna, a saber: a) adequação e eficácia do controle interno; b) confiabilidade das informações; c) integridade do sistema contábil e de controle interno; e, d) compatibilidade das operações e programas, com os devidos objetivos, assim como os planos e os meios de execução estabelecidos.

\subsection{Auditoria Independente}

Esta modalidade de auditoria atua com profissionais independentes, sem vínculo empregatício com a instituição auditada e relacionamento pessoal com os seus gestores. Tal independência livre de compromissos pessoais agrega maior confiabilidade à empresa auditada, principalmente para investidores, agências de financiamentos, fornecedores e analistas financeiros (CREPALDI, 2013).

A auditoria independente tem por desígnio assegurar em nível razoável, que as demonstrações contábeis como um todo, estão livres de distorção relevante, por meio de opinião do auditor independente e o cumprimento das normas de auditoria independente. Diante dessa investigação na qual o auditor exerce, as Normas Brasileiras de Contabilidade-NBCs exigem que o profissional obtenha segurança razoável em emissão de sua opinião sobre as demonstrações contábeis, assegurando que estejam livres de distorções relevantes, independente se a causa for erro ou fraude. (CFC, 2016).

Santos e Pereira (2003), exemplificam que os auditores independentes podem apresentar parecer sem ressalva, com ressalva, parecer adverso ou pode abster de opinião. O parecer sem ressalva indica que as demonstrações contábeis estão em conformidade com os princípios e normas fundamentais de contabilidade e foram expostos os assuntos relevantes. No parecer com ressalva o auditor constata incoerências nas demonstrações, mas não acredita que afetará em magnitude suficiente para gerar parecer adverso ou abstenção de opinião.

O parecer adverso é gerado em ocasiões nas quais é constatada existência de distorções que comprometam o conjunto das demonstrações contábeis. Em casos de abstenção de opinião o exame aplicado pelo auditor sofre limitações que impossibilitaram a formulação de opinião sobre as demonstrações contábeis.

$\mathrm{O}$ auditor deve avaliar os riscos que a auditoria pode sofrer, considerando o ambiente de controle da instituição (CREPALDI, 2013). Os riscos para este tipo de auditoria são os de distorções relevantes, que pode ser no nível geral das demonstrações contábeis ou na afirmação das classes saldos, transações e divulgações. Além desta modalidade, existem também os riscos de detecção, que tem posição inversa aos riscos de distorções relevantes, pois quanto maiores a distorções menores serão os riscos de detecção (CFC, 2016). 


\subsection{Erros e Fraudes}

Entende-se por fraude o ato intencional de omissão ou manipulação das transações, documentos, registros e demonstrações contábeis. Define-se erro como o ato não intencional na elaboração dos registros e demonstrações contábeis (CFC, 2003).

A detecção de fraude e erros precisa ser criteriosa, referente todo sistema contábil, incluindo o controle interno, tanto em termos de concepção quanto de funcionamento efetivo, mantendo atenção especial a possíveis eventualidades que possam ocasionar erro e fraude.

Em concordância com o ponto de vista dos entrevistados nesta pesquisa, Pinheiro e Cunha (2003) afirmam que muitas organizações acreditam que o principal objetivo de uma auditoria é descobrir, ou se proteger contra fraudes e de evitar multas fiscais, porém, esquecem-se da importância desta na contribuição com a eficácia e eficiência interna.

Porém, Crepaldi (2013) afirma que o auditor não deve ser responsabilizado pela prevenção de fraudes ou erros, mas em seu planejamento de trabalho deve avaliar os riscos de ocorrência e indagar a administração da instituição auditada sobre qualquer tipo de anomalia que venha a ser um possível vestígio de fraude ou erro.

\subsection{Teoria dos escândalos corporativos}

Para Condé, Almeida e Quintal (2015), suas perspectivas deduzem que nas grandes corporações um dos maiores problemas da atualidade são as fraudes nas demonstrações financeiras, podendo afetar a gama de investidores e sociedade. Geralmente o ato de fraudar, possui o intuito de agregar benefícios ao agente fraudador, mesmo que esteja gerando malefícios há outros agentes da instituição ou à sociedade.

Os resultados do estudo de Silva et al. (2012) apresentam diferenças de adulterações nos lucros das organizações, entre os países. Nos EUA são acrescidos da realidade, trazendo uma ideia de que a rentabilidade e crescimento da instituição são maiores do que realmente são para atrair mais investidores. No Brasil é mais comum as instituições fraudulentas diminuírem o valor real dos lucros para reduzir a incidência de tributos no montante real.

Condé, Almeida e Quintal (2015) descreveram em seu literário, que em economias menos transparentes como o caso da Europa, a manipulação das demonstrações contábeis é menos ocasional, devido aos administradores não terem benefícios promovendo fraudes. Já nos EUA onde a transparência é mais desejada, a ocasião de fraudes é mais sucinta, devido ao desejo de sucesso dos administradores, afetados por vossas ganâncias.

\subsection{Estudos similares anteriores}


O estudo de Pereira e Nascimento (2005) demonstra que as fraudes podem se apresentar de quatro tipos: fraudes contábeis, fraudes financeiras, fraudes no controle interno e fraudes éticas. As fraudes contábeis são as que ocorrem nas demonstrações contábeis. Uma ferramenta significativa para a descoberta deste tipo de fraude é a contabilidade, por meio de seus próprios relatórios podem ser constatados de fato onde está acontecendo o ato fraudulento.

As fraudes financeiras atingem diretamente as operações monetárias no ambiente interno da empresa, geralmente são as transferências de bens para familiares ou nomes "fantasmas", e entre outras formas, torna-se a forma mais acessível de cometer a fraude. Por fim, a fraude ética não está ligada aos problemas físicos e materiais da empresa, mas ao ataque intangível, que causa grandes dificuldades para a entidade.

Oliveira e Santos (2007), em sua pesquisa concluíram que, os interesses do auditor se relacionam, especificamente, a atos fraudulentos que distorcem de forma relevante as demonstrações contábeis. É cargo do auditor detectar fraudes ou erros em evidências da auditoria, aqueles nos quais fazem com que o profissional tenha total segurança nos resultados encontrados.

\section{METODOLOGIA}

Em relação ao problema, a pesquisa é de natureza qualitativa, pois possuiu caráter exploratório qualitativo que estimula o pensar e falar livremente.

Este tipo de pesquisa permite a apuração de dados a partir do uso de instrumentos padronizados (questionário), permitindo a análise de projeções que testarão a hipótese (LAKATOS; MARCONI, 2003). De acordo com Minayo e Sanches (1993), existe relação entre a objetividade e subjetividade, podendo o estudo qualitativo gerar questões para serem aprofundadas quantitativamente, e vice-versa.

Quanto aos objetivos este estudo se classifica como descritivo. Segundo Cervo e Bervian (2002), a pesquisa descritiva observa, registra, analisa e correlacionada fatos e fenômenos, sem manipulação da pesquisa.

Em relação aos procedimentos de pesquisa optou-se pelo estudo de caso em uma empresa de diversos ramos, desde indústria até o agronegócio, instalada na cidade de Douradina - Estado do Paraná. O levantamento dos dados ocorreu com a utilização do software Survio ${ }^{\circledR}$ com 09 (nove) perguntas fechadas ao auditor interno, sendo 3 (três) para definir o perfil, 2 (dois) para diagnosticar a formação acadêmica e 4 (quatro) sobre o uso da auditoria. Em contrapartida, foram feitas 12 (doze) perguntas fechadas ao gestor, sendo 3 (três) perguntas para identificar o perfil, 2 (duas) para diagnosticar sua formação acadêmica, 2 (duas) referente sua função na empresa e 6 (seis) sobre o uso da auditoria. 
Este estudo se desenvolveu em nove etapas, primeiro foi escolhido o estabelecimento do tema de estudo. Em seguida foi realizada a análise da problematização, reflexão e o estabelecimento da justificativa; assim como a análise das hipóteses; definição dos objetivos gerais e específicos; estabelecimento da metodologia de pesquisa; estabelecimento do cronograma de execução; revisão da literatura e análise dos resultados obtidos.

\section{RESULTADOS E DISCUSSÃO}

Em 1966, aos 16 anos, um jovem empreendedor trabalhava em uma das muitas lojas que sofriam com a crise financeira que assolava o país. Ao saber da intenção do proprietário em vender o estabelecimento, o empreendedor imediatamente reconheceu uma excelente oportunidade de negócio. Sua visão de futuro foi compartilhada com seu pai, que sem perder tempo, entregou o Jeep da família e parte da chácara onde moravam em troca da loja. Ao enxergar oportunidade onde muitos só viam crise, José deu início a história de sucesso da organização.

A loja teve início em Douradina, interior do Estado do Paraná, Brasil, e atualmente é uma das maiores empresas do Brasil, com 243 lojas de varejo em 9 estados, além de 5 indústrias de colchões e estofados, 1 indústria de molas e 13 centros de distribuição de mercadorias.

Como missão, o grupo empresarial tem como objetivo oferecer sempre o melhor em produtos e serviços, com atendimento diferenciado. Até o ano de 2019, os gestores da empresa objetivam ser a número 1 do Brasil, considerando melhor lugar para se trabalhar, e se enquadrar entre as 200 maiores empresas do país.

Em uma gestão voltada à valorização das pessoas e fazendo negócios sustentáveis, a empresa procura compreender o cliente e ganhar sua confiança, entendendo que esse é um diferencial competitivo para conseguir atingir seus objetivos.

O gestor atual da empresa encontra-se na faixa etária de 35 a 50 anos, é casado, graduado em Ciências Contábeis com especialização na mesma área, gerente do setor de indústria e exercendo atividade na função atual de 6 a 10 anos.

Esse relatou que a empresa possui auditoria interna. Os principais motivos para a contratação e/ou manutenção desta atividade são: agregar valor à entidade, podendo assim obter a confirmação do cumprimento das legislações

e normas; detectar erros e fraudes e, assim adquirir segurança para impedir que ocorram distorções das demonstrações contábeis; obter melhorias de processos; e redução dos custos.

O auditor interno da empresa apresenta-se na faixa etária de 35 a 50 anos, casado, graduado em Ciências Contábeis com MBA na área, como auditor 
interno e exercendo atividade na função atual de 16 a 20 anos, nunca trabalhou como auditor independente.

Assim como o gestor, esse profissional afirma que, a contratação da auditoria independente serve para examinar o cumprimento das legislações e normas, principalmente relacionadas à elaboração das demonstrações contábeis, assim agregar valor à entidade. Detectar erros e fraudes, buscar melhorias de processos e a redução de custos são objetivos raros para a contratação da auditoria independente.

\section{CONSIDERAÇÕES FINAIS}

Considerando a análise dos dados das entrevistas realizadas, observa-se que a detecção de erros e fraudes não corresponde ao principal objetivo da contratação da auditoria contábil. Foi possível verificar que tanto o gestor quanto o auditor acreditam que a auditoria visa a agregar valor à empresa, mas também auxiliar na redução de custos e na a melhoria dos processos, entre outros.

Sendo assim, conclui-se que, erros e fraudes não correspondem a uma preocupação específica para os envolvidos nesta pesquisa. Isso pode ser resultado da crença de que a própria agregação de valores, que ambos apontaram como um fator importante seja uma consequência positiva da auditoria, capaz de garantir por si só, a diminuição de erros e da possibilidade de fraudes.

Sendo assim, entende-se que a contribuição da auditoria interna para os gestores vai além dos exames para identificar erros. A auditoria interna contribui com a disponibilização de dados e informação que apresentam o perfil administrativo e produtivo atual da empresa, dando assim suporte necessário para as tomadas de decisões, com maiores possibilidades de serem ações assertivas.

Para estudos futuros recomenda-se efetuar a pesquisa em multicasos e diferentes regiões brasileiras e internacionais.

\section{REFERÊNCIAS}

ATTIE, W. Auditoria interna. São Paulo: Atlas, 1998.

ATTIE, W. Auditoria: conceitos e aplicações. 6. ed. São Paulo: Atlas, 2011.

CERVO; A. L, BERVIAN; P. A. Metodologia científica. 3. ed. São Paulo: Makron, 1983.

CFC, CONSELHO FEDERAL DE CONTABILIDADE. NBC TA 200 (R1), 05 de setembro de 2016. - Objetivos gerais do auditor independente e a condução 
da auditoria em conformidade com normas de auditoria. Disponível em: $<\mathrm{http}$ :/ www1.cfc.org.br/sisweb/SRE/docs/RES_1203.pdf>. Acesso em: 05 mai. 2017.

CFC, CONSELHO FEDERAL DE CONTABILIDADE. Resolução CFC $\mathbf{n}^{\mathbf{0}}$ 986, 28 de novembro de 2003. Aprova a NBC TI 01 - Da auditoria interna. Disponível em: <http://www1.cfc.org.br/sisweb/SRE/docs/RES_986.pdf>. Acesso em: 02 mai. 2017.

CONDÉ, R. A. D.; ALMEIDA, C. O. F.; QUINTAL, R. S. Fraude contábil: análise empírica à luz dos pressupostos teóricos do triângulo da fraude e dos escândalos corporativos. Gestão \& Regionalidade, v. 31, n. 93, p. 94-108, 2015. Disponível em: <http://www.spell.org.br/documentos/ver/38604/fraudecontabil--analise-empirica-a-luz-dos-pressupostos-teoricos-do-triangulo-dafraude-e-dos-escandalos-corporativos-/i/pt-br>. Acesso em: 29 jul. 2017.

CREPALDI, S. A. Teoria e prática. 9. ed. São Paulo: Atlas, 2013.

LAKATOS, E. M.; MARCONI, M. A. Fundamentos de metodologia científica. 5. ed. São Paulo: Atlas, 2003.

LUCAS, D. R. et al. Auditoria interna é importante. Disponível em: $<$ http:// www.inicepg.univap.br/cd/INIC_2009/anais/arquivos/RE_0079_0164_03.pdf>. Acesso em: 18 nov. 2017.

MINAYO, M. C. S; SANCHES, O. Quantitativo, qualitativo: oposição e complementariedade? Metodologia de pesquisa qualitativa em saúde. Cadernos de saúde pública, v. 9, p. 3, jul/set. 1993. Disponível em: $<$ http:// www.ufjf.br/especializacaofisioto/files/2010/03/Quantitativo-qualitativooposi $\% \mathrm{C} 3 \% \mathrm{~A} 7 \% \mathrm{C} 3 \% \mathrm{~A} 3 \mathrm{o}-\mathrm{ou}-\mathrm{complementaridade1.pdf}>$. Acesso em: 11 ago. 2017.

OLIVEIRA, A. Q.; SANTOS, N. M. B. F. D. Rodízio de firmas de auditoria: a experiência brasileira e as conclusões do mercado. Revista Contabilidade \& Finanças - USP, v. 18, n. 45, p. 91-100, 2007. Disponível em: <http://www.spell. org.br/documentos/ver/24318/rodizio-de-firmas-de-auditoria--a-experienciabrasileira-e-as-conclusoes-do-mercado/i/pt-br>. Acesso em: 10 jun. 2017.

PEREIRA, A. C.; NASCIMENTO, W. S. do. Um estudo sobre a atuação da auditoria interna na detecção de fraudes nas empresas do setor privado do estado de São Paulo. Revista Brasileira de Gestão de Negócios. FECAP, São Paulo, v. 7, n. 19, p. 46-56, set./dez. 2005. Disponível em: <http://www.spell.org.br/ 
documentos/ver/6468/um-estudo-sobre-a-atuacao-da-auditoria-interna-nadeteccao-de-fraudes-nas-empresas-do-setor-privado-no-estado-de-sao-paulo $>$. Acesso em: 15 jun. 2017.

PINHEIRO, G. J.; CUNHA, L. R. S. A importância da auditoria na detecção de fraudes. Contabilidade Vista \& Revista, Belo Horizonte, v. 14, n. 1, p. 31-48, 2003. Disponível em: <http://revistas.face.ufmg.br/index.php/ contabilidadevistaerevista/article/view/210>. Acesso em: 21 jul. 2017.

RODRIGUES, J. C. S. Manual de auditoria interna. Redenção: UNILAB, 2012.

SANTOS, E. C.; PEREIRA, A. C. O Parecer dos Auditores Independentes sobre Demonstrações Contábeis: uma abordagem sobre o parecer-padrão, atualmente em vigor no Brasil. Revista Brasileira de Contabilidade do CFC, Brasília, n. ${ }^{o}$ 139, p. 71-81, maio/jun. 2003. Disponível em: <https://s3.amazonaws.com/ academia.edu.documents/34478151/art5033_2.pdf?AWSAccessKeyId=AKIA IWOWYYGZ2Y53UL3A\&Expires $=1509672937 \&$ Signature $=i Q 7 V B O T s q u$ 4c0X89W49IpJJ0he0\%3D\&response-content-disposition=inline \%3B\%20filename\%3DO_Parecer_dos_Auditores_Independentes_so.pdf $>$. Acesso em: 02 out. 2017.

SILVA, A. H. C. et al. Teoria dos escândalos corporativos: uma análise comparativa de casos brasileiros e norte-americanos. Revista de Contabilidade do Mestrado em Ciências Contábeis da UERJ, v. 17, n. 1, p. 92-108, 2012. Disponível em: <http://www.spell.org.br/documentos/ver/7625/teoria-dosescandalos-corporativos--uma-analise-comparativa-de-casos-brasileiros-enorteamericanos/i/pt-br>. Acesso em: 29 jul. 2017. 